\title{
Short Communication Exposure to animals and increased risk of marginal zone B-cell lymphomas of the ocular adnexae
}

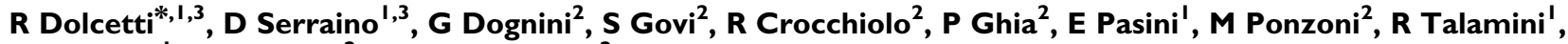 \\ P De Paoli', C Doglioni ${ }^{2}$ and AJM Ferreri ${ }^{2}$
}

'Centro di Riferimento Oncologico - IRCCS, National Cancer Institute, 3308I, Aviano, Italy; ${ }^{2}$ Unit of Lymphoid Malignancies, Department of Onco-Hematology, San Raffaele Scientific Institute, 20132 , Milan, Italy

BACKGROUND: Ocular adnexal marginal zone B-cell lymphoma (OAMZL) has been associated with Chlamydophila psittaci, an infection that may be transmitted by carrier animals. However, it is still unclear whether exposure to animals affects the risk of $O A M Z L$ in comparison with other lymphoma histotypes. We therefore investigated the role of professional and/or domestic exposures to animals in the occurrence of $O A M Z L$, as compared with other types of lymphoma.

METHODS: A hospital-based case-control study was carried out on 43 consecutive OAMZL patients (cases) and 87 consecutive patients with nodal non-Hodgkin's lymphomas (NHLs; controls). Multiple logistic regression (MLR) odds ratios (ORs), and 95\% confidence intervals (Cls) were used to estimate the association between exposures to animals and OAMZL risk.

RESULTS: A higher proportion of cases reported a lifetime exposure to household animals (79.1\% vs $64.4 \%$ among controls), with a non-statistical significant MLR-OR of 2.18 (95\% Cl: $0.85-5.62)$. The OAMZL cases more frequently reported a history of occupation in breeding and/or slaughtering than controls (34.9\% vs 6.9\%), with an overall increased risk of 7.69 (95\% Cl: 2.65-22.34).

CONCLUSION: These results indicate that, compared with nodal NHLs, the risk of OAMZL is markedly increased by contact with animals, particularly by occupational exposures.

British Journal of Cancer (2012) I 06, 966-969. doi:I0.1038/bjc.2012.2 www.bjcancer.com

Published online 24 January 2012

(c) 2012 Cancer Research UK

Keywords: non-Hodgkin's lymphomas; ocular adnexal marginal zone B-cell lymphoma epidemiology; animal exposure;

Chlamydophila psittaci

Non-Hodgkin's lymphomas (NHLs) constitute a heterogeneous group of malignancies whose aetiology remains elusive (Blinder and Fisher, 2008). The incidence of NHLs has risen steadily in many countries during the last decades, although this cannot be entirely attributable to improved diagnosis or classification (Adamson et al, 2007; Bosetti et al, 2008). Underlying autoimmunity and exposure to environmental, occupational, or infectious agents have been suggested to increase the risk of NHLs (Guidoboni et al, 2006; Alexander et al, 2007; Blinder and Fisher, 2008; Hjalgrim and Engels, 2008; Marcucci and Mele, 2011). Several animals may be carriers of lymphomagenic infectious agents, and indeed elevated risks have been variably associated with contacts to livestock (Amadori et al, 1995; Svec et al, 2005; Tranah et al, 2008), or with occupational exposure to meat (Fritschi et al, 2002; McLean and Pearce, 2004). However, as available evidence is inconclusive (Moore et $a l, 2007$ ), as a likely consequence of NHL heterogeneity, subtype-specific aetiological research is required.

Ocular adnexal lymphomas represent relatively rare lymphoproliferative disorders whose incidence is rising (Moslehi et al, 2006). Extranodal marginal zone B-cell lymphoma (ocular adnexal marginal

*Correspondence: Dr R Dolcetti; E-mail: rdolcetti@cro.it

${ }^{3}$ These authors contributed equally to this work.

Received 2 August 2011; revised 22 December 2011; accepted 27

December 201 I; published online 24 January 2012 zone B-cell lymphoma (OAMZL)) is the commonest entity, and it has been strongly associated with Chlamydophila psittaci $(C p)$ infection (Ferreri et al, 2004, 2009). This association has been demonstrated with several detection methods, including different PCR protocols, immunohistochemistry, immunofluorescence, and electronic microscopy (Ponzoni et al, 2008). Importantly, viable $C P$ has been in vitro isolated from OAMZL patients (Ferreri et al, 2008). Chlamydophila psittaci is the aetiological agent of psittacosis, a human zoonotic disease caused by exposure to infected animals, mostly birds but also domestic mammals and pets (Beeckman and Vanrompay, 2009; Sprague et al, 2009). A previous investigation has suggested that contact with household animals is more common among OAMZL patients than in healthy individuals (Ferreri et al, 2008). It remains to be clarified, however, whether exposure to animals affects the risk of OAMZL in comparison with patients affected by other types of NHLs. We therefore investigated the role of professional and/or domestic exposures to animals in the occurrence of OAMZL, as compared with the occurrence of other types of lymphoma.

\section{PATIENTS AND METHODS}

A hospital-based, case-control study was conducted at the San Raffaele Scientific Institute, Milan, Northern Italy, after approval by the local IRB, between June 2004 and December 2009. Data were from 43 consecutive OAMZL patients (the cases; 
Table I Description of the study population according to socio-demographic characteristics and tumour histology (Italy, 2004-2009)

\begin{tabular}{|c|c|c|c|}
\hline & $\begin{array}{c}\text { Cases } \\
(n=43) \\
\text { No. }(\%)\end{array}$ & $\begin{array}{c}\text { Controls } \\
(n=87) \\
\text { No. }(\%)\end{array}$ & $P$-value \\
\hline \multicolumn{4}{|l|}{ Sex } \\
\hline Female & $29(67.4)$ & $44(50.6)$ & \\
\hline Male & $14(32.6)$ & $43(49.4)$ & 0.10 \\
\hline \multicolumn{4}{|l|}{ Age } \\
\hline$\leqslant 54$ & $16(37.2)$ & $23(26.4)$ & \\
\hline $55-69$ & $15(34.9)$ & $32(36.8)$ & \\
\hline$\geqslant 70$ & $12(27.9)$ & $32(36.8)$ & 0.40 \\
\hline \multicolumn{4}{|l|}{ Years of education ${ }^{\mathrm{a}}$} \\
\hline$\leqslant 5$ & $9(22)$ & $23(28.4)$ & \\
\hline $6-13$ & $26(63.4)$ & $51(63.0)$ & \\
\hline$\geqslant 14$ & $6(14.6)$ & $7(8.6)$ & 0.51 \\
\hline \multicolumn{4}{|l|}{ Lymphoma histology $^{\mathrm{b}}$} \\
\hline Extranodal marginal zone lymphoma & $43(100)$ & - & \\
\hline Nodal marginal zone lymphoma & - & $4(4.6)$ & \\
\hline Diffuse large B-cell lymphoma & - & $49(56.3)$ & \\
\hline Follicular lymphoma & - & $32(36.8)$ & \\
\hline Small lymphocytic lymphoma & - & $2(2.3)$ & \\
\hline
\end{tabular}

${ }^{a}$ The sum does not add up to the total because of missing values. ${ }^{b}$ All diagnoses were confirmed by central pathology review.

median age: 60.0 years) and 87 consecutive control patients with nodal NHLs (median age: 65.0 years; Table 1). A standardised and validated questionnaire was used to investigate the lifetime history of occupational and domestic exposure to cats, dogs, birds, and other pets (all vertebrates included). All cases and controls were HIV-negative, while 31/43 OAMZL cases were $C p$-associated, as demonstrated by the presence of $C p$ DNA in tumour tissues (Ferreri et al, 2004). Multiple logistic regression (MLR), odds ratios (ORs), and $95 \%$ confidence intervals (CIs) were used to estimate the association between the above-mentioned exposures and the occurrence of OAMZL (Breslow and Day, 1980).

\section{RESULTS}

Overall, lifetime exposure to domestic animals was more frequently reported by cases $(79.1 \%)$ than controls $(64.4 \%)$, with a non-statistical significant 2.2 -fold increased risk of OAMZL (Table 2). The risk of OAMZL was significantly associated with domestic exposure to dogs, with a 3-fold increase $(95 \%$ CI:1.00-9.05). Conversely, increased, but non-statistically significant, ORs emerged with regard to exposure to cats and birds.

As compared with $6.9 \%$ of controls, $34.9 \%$ of cases reported a lifetime occupational exposure to animals (MLR-OR:7.69; 95\% CI: 2.65-22.34). In particular, $27.9 \%$ of cases were involved in slaughtering with a MLR-OR of 16.65 (lower 95\% CI: 3.47; Table 2). These results were confirmed when the analysis was restricted to the $31 \mathrm{Cp}$-associated OAMZL (data not shown in tables). Lifetime exposure to all types of domestic animals was associated with a 2.44-fold higher risk of OAMZL (95\% CI:0.78-7.57), with non significantly elevated risks for exposure to cats $(M L R-O R=3.29)$ and/or dogs $(M L R-O R=3.15)$. Significantly elevated MLR-OR were noted among $C p$-positive cases for occupational exposure, with a 9-fold increase for all types of exposure (MLR-OR $=9.22$, 95\% CI: 2.92-29) and a 21-fold higher risk associated with slaughtering (95\% CI: 4.21-107; data not shown in tables).

The analysis was also stratified according to the histological diagnosis of controls, by separately comparing the 43 OAMZL
Table 2 Association between exposure to animals and diagnosis of ocular adnexal lymphoma (Italy, 2004-2009)

\begin{tabular}{lccc}
\hline & $\begin{array}{c}\text { Cases } \\
\text { no. (\%) }\end{array}$ & $\begin{array}{c}\text { Controls } \\
\text { no. (\%) }\end{array}$ & $\begin{array}{c}\text { MLR-OR } \\
(\mathbf{9 5 \%} \text { CI) }\end{array}$ \\
\hline $\begin{array}{l}\text { History of exposure to domestic animals } \\
\text { No }\end{array}$ & $9(20.9)$ & $31(35.6)$ & $\mid$ \\
Yes, all & $34(79.1)$ & $56(64.4)$ & $2.18(0.85-5.62)$ \\
Cats & 20 & 34 & $2.29(0.84-6.28)$ \\
Dogs & 19 & 25 & $3.00(1.00-9.05)$ \\
Birds & 18 & 26 & $2.00(0.67-5.97)$ \\
History of occupational exposure to animals & & \\
No & $28(65.1)$ & $81(93.1)$ & \\
Yes, all & $15(34.9)$ & $6(6.9)$ & $7.69(2.65-22.34)$ \\
Slaughter & 12 & 2 & $16.65(3.47-80.02)$ \\
Breeding & 3 & 4 & $2.65(0.53-13.17)$ \\
\hline
\end{tabular}

aultiple logistic regression (MLR) odds ratios (ORs) adjusted for sex, age and, when appropriate, history of occupational exposure to animals (no/yes).

Table 3 MLR, ORs, and 95\% Cls for developing OAMZL by exposures to animals and histological diagnosis of controls (Italy, 2004-2009)

\section{MLR-OR (95\% Cl)}

DLBCL NHL controls

FL NHL controls

\begin{tabular}{|c|c|c|}
\hline \multicolumn{3}{|c|}{ History of exposure to domestic animals } \\
\hline No & I & I \\
\hline Yes, all & $1.47(0.47-4.54)$ & $1.74(0.5 \mid-5.88)$ \\
\hline Cats & $1.80(0.53-6.06)$ & $1.83(0.47-7.11)$ \\
\hline Dogs & $1.48(0.35-6.27)$ & $2.9 \mid(0.03-\mid 1.65)$ \\
\hline \multicolumn{3}{|c|}{ History of occupational exposure to animals } \\
\hline No & 1 & 1 \\
\hline Yes, all & $8.61(2.09-36)$ & $9.26(1.90-45)$ \\
\hline Slaughter & $18.18(2.13-142)$ & $13.89(1.66-111)$ \\
\hline Breeding & $2.8 \mathrm{I}(0.37-2 \mathrm{I})$ & $4.76(0.45-50)$ \\
\hline Birds & $2.15(0.47 .9 .82)$ & $1.48(0.37-5.86)$ \\
\hline
\end{tabular}

Abbreviations: $\mathrm{Cl}=$ confidence intervals; $\mathrm{DLBCL}=$ diffuse large $\mathrm{B}$ cell lymphoma: $\mathrm{FL}=$ follicular lymphoma; $M L R=$ multiple logistic regression; ORs=odds ratios; $\mathrm{OAMZL}=$ ocular adnexal marginal zone B-cell lymphoma. ${ }^{\mathrm{a}} \mathrm{MLR}$ ORs adjusted for sex, age and, when appropriate, history of occupational exposure to animals (no/yes).

cases with the 49 controls diagnosed with a diffuse large B-cell lymphoma (DLBCL), or with the 32 controls diagnosed with a follicular lymphoma (FL; Table 3). The comparison with both control groups confirmed the increased risks in OAMZL patients associated with overall occupational exposure to animals (MLR$\mathrm{OR}=8.61$ and MLR-OR $=9.26$ for DLBCL and FL, respectively) and with slaughtering in particular (MLR-OR $=18.18$ and MLR-OR $=13.89$ for DLBCL and FL, respectively). No statistically significant elevated risks were found for breeding or exposures to domestic animals (Table 3 ).

\section{DISCUSSION}

To our knowledge, this is the first epidemiological investigation suggesting that contact with animals is associated with increased risk of OAMZL, even in comparison with other NHL entities. This association seems to be particularly strong for occupational exposure to animals or their products. Previous studies reported a globally increased risk of NHL among individuals exposed to livestock, mainly cattle and pigs (Amadori et al, 1995; Svec et al, 2005; Tranah et al, 2008), or working with meat (Fritschi et al, 
2002; McLean and Pearce, 2004), although these associations were not confirmed (Holly et al, 1997; Persson and Fredrikson, 1999; Dryver et al, 2004; Moore et al, 2007). These inconsistencies may be due to the fact that NHLs were considered as a single entity or that only the major NHL histotypes were analysed. In this study, the analysis of a relatively large series of NHL of a distinct histotype and arising from the same extra-nodal district allowed the identification of a previously unrecognised association of OAMZL with occupational exposure to animals, highlighting a markedly increased risk. This was particularly evident for slaughterhouse workers, both overall and when cases were separately compared with DLBCL controls or FL controls. This observation reinforced the notion that working in the meat industry entails several potentially hazardous exposures, potentially including infectious agents. Available evidence, however, does not support a pathogenic role for zoonotic viruses, such as retroviruses and herpes viruses, specific to beef cattle and chicken (Bender et al, 1988; Lee et al, 2005). The associations observed in our study were even stronger when the analysis was restricted to $C p$-positive case, thus pointing to the transmission of $C p$ infection as a likely relevant risk factor.

Our findings also provide novel insights into the still controversial issue of the association between contacts with pets and NHL risk (Holly et al, 1997; Persson and Fredrikson, 1999; Dryver et al, 2004; Tranah et al, 2008). We found a borderline significant increase of OAMZL risk associated with exposure to one or more domestic animals, especially to dogs. Our results may be consistent with the peculiar pathogenic mechanisms proposed for OAMZL, which likely involve a chronic stimulation by exogenous antigen(s) (Ferreri et al, 2009). In this scenario, contacts with domestic animals may favour the transmission of infectious agents that, under still poorly defined circumstances, may trigger and sustain B-cell lymphoproliferation. The further increased risk of OAMZL detected when only $C p$-associated cases were analysed is consistent with this hypothesis. Intriguingly, we observed an increased risk for $C p$-associated OAMZL for individuals exposed to dogs, even if these animals are presently not considered the main vehicle of $C p$ transmission to humans. Indeed, $C p$ infection may well be detected in dogs (Fukushi et al, 1985; Sprague et al, 2009), even in public areas where contamination by potentially zoonotic pathogens seems unlikely (Tarsitano et al, 2010). This picture is similar to what is emerging for gastric lymphomagenesis sustained by Helicobacter strains different from Helicobacter pylori, which originate from contacts with domestic animals (Haesebrouck et al, 2009).

Possible limitations of this study include the relatively undersized investigated sample and the fact that the recruitment of cases and controls was hospital-based. Considering the relative rarity of OAMZL, we were able to collect a series of 43 cases large enough to obtain results of statistical significance with substantial increased risks (i.e., 3-fold or higher after adjustment for potential confounders). It should be admitted, however, that the relative small number of cases limited the analysis stratified by histological types. Although cases and controls were carefully matched for age and sex, a slightly higher fraction of females was included in the case group. This was due to the higher prevalence of OAMZL among women (Ferreri et al, 2009).

In conclusion, this case-control study indicates that domestic or occupational contacts with animals increase the risk to develop OAMZL. These findings further stimulate new investigations aimed at identifying the aetiologic agents related to this exposure and involved in OAMZL pathogenesis.

\section{ACKNOWLEDGEMENTS}

This work was supported by the Associazione Italiana per la Ricerca sul Cancro (AIRC; 1031 to RD and 9226 to CD) and Fondazione Federica per la Vita. EP is a fellow of the Fondazione Italiana per la Ricerca sul Cancro (FIRC).

\section{REFERENCES}

Adamson P, Bray F, Costantini AS, Tao MH, Weiderpass E, Roman E (2007) Time trends in the registration of Hodgkin and non-Hodgkin lymphomas in Europe. Eur J Cancer 43: $391-401$

Alexander DD, Mink PJ, Adami HO, Chang ET, Cole P, Mandel JS, Trichopoulos D (2007) The non-Hodgkin lymphomas: a review of the epidemiologic literature. Int J Cancer 120(Suppl 12): 1-39

Amadori D, Nanni O, Falcini F, Saragoni A, Tison V, Callea A, Scarpi E, Ricci M, Riva N, Buiatti E (1995) Chronic lymphocytic leukaemias and non-Hodgkin's lymphomas by histological type in farming-animal breeding workers: a population case-control study based on job titles. Occup Environ Med 52: 374-379

Beeckman DS, Vanrompay DC (2009) Zoonotic Chlamydophila psittaci infections from a clinical perspective. Clin Microbiol Infect 15: 11-17

Bender AP, Robison LL, Kashmiri SV, McClain KL, Woods WG, Smithson WA, Heyn R, Finlay J, Schuman LM, Renier C (1988) No involvement of bovine leukemia virus in childhood acute lymphoblastic leukemia and non-Hodgkin's lymphoma. Cancer Res 48: 2919-2922

Blinder V, Fisher SG (2008) The role of environmental factors in the etiology of lymphoma. Cancer Invest 26: 306-316

Bosetti C, Levi F, Ferlay J, Lucchini F, Negri E, La VC (2008) Incidence and mortality from non-Hodgkin lymphoma in Europe: the end of an epidemic? Int J Cancer 123: 1917-1923

Breslow NE, Day NE (1980) Statistical Methods in Cancer Research. Vol. I. The Analysis of Case-control Studies. No. 32ed. IARC Scientific Publications: Lyon, France, pp 192-247

Dryver E, Brandt L, Kauppinen T, Olsson H (2004) Occupational exposures and non-Hodgkin's lymphoma in Southern Sweden. Int J Occup Environ Health 10: $13-21$

Ferreri AJ, Dolcetti R, Dognini GP, Malabarba L, Vicari N, Pasini E, Ponzoni M, Cangi MG, Pecciarini L, Resti AG, Doglioni C, Rossini S, Magnino S (2008) Chlamydophila psittaci is viable and infectious in the

conjunctiva and peripheral blood of patients with ocular adnexal lymphoma: results of a single-center prospective case-control study. Int J Cancer 123: 1089-1093

Ferreri AJ, Dolcetti R, Magnino S, Doglioni C, Ponzoni M (2009) Chlamydial infection: the link with ocular adnexal lymphomas. Nat Rev Clin Oncol 6: 658-669

Ferreri AJ, Guidoboni M, Ponzoni M, De CC, Dell'Oro S, Fleischhauer K, Caggiari L, Lettini AA, Dal Cin CE, Ieri R, Freschi M, Villa E, Boiocchi M, Dolcetti R (2004) Evidence for an association between Chlamydia psittaci and ocular adnexal lymphomas. J Natl Cancer Inst 96: 586-594

Fritschi L, Johnson KC, Kliewer EV, Fry R (2002) Animal-related occupations and the risk of leukemia, myeloma, and non-Hodgkin's lymphoma in Canada. Cancer Causes Control 13: 563-571

Fukushi H, Ogawa H, Minamoto N, Hashimoto A, Yagami K, Tamura H, Shimakura S, Hirai K (1985) Seroepidemiological surveillance of Chlamydia psittaci in cats and dogs in Japan. Vet Rec 117: $503-504$

Guidoboni M, Ferreri AJ, Ponzoni M, Doglioni C, Dolcetti R (2006) Infectious agents in mucosa-associated lymphoid tissue-type lymphomas: pathogenic role and therapeutic perspectives. Clin Lymphoma Myeloma 6: $289-300$

Haesebrouck F, Pasmans F, Flahou B, Chiers K, Baele M, Meyns T, Decostere A, Ducatelle R (2009) Gastric helicobacters in domestic animals and nonhuman primates and their significance for human health. Clin Microbiol Rev 22: 202-223

Hjalgrim H, Engels EA (2008) Infectious aetiology of Hodgkin and nonHodgkin lymphomas: a review of the epidemiological evidence. J Intern Med 264: $537-548$

Holly EA, Lele C, Bracci P (1997) Non-Hodgkin's lymphoma in homosexual men in the San Francisco Bay Area: occupational, chemical, and environmental exposures. J Acquir Immune Defic Syndr Hum Retrovirol 15: $223-231$ 
Lee J, Kim Y, Kang CS, Cho DH, Shin DH, Yum YN, Oh JH, Kim SH, Hwang MS, Lim CJ, Yang KH, Han K (2005) Investigation of the bovine leukemia virus proviral DNA in human leukemias and lung cancers in Korea. J Korean Med Sci 20: 603-606

Marcucci F, Mele A (2011) Hepatitis viruses and non-Hodgkin lymphoma: epidemiology, mechanisms of tumorigenesis, and therapeutic opportunities. Blood 117: $1792-1798$

McLean D, Pearce N (2004) Cancer among meat industry workers. Scand J Work Environ Health 30: 425-437

Moore T, Brennan P, Becker N, de SS, Maynadie M, Foretova L, Cocco P, Staines A, Nieters A, Font R, Mannetje A, Benhaim-Luzon V, Boffetta P (2007) Occupational exposure to meat and risk of lymphoma: a multicenter case-control study from Europe. Int J Cancer 121: 2761 - 2766

Moslehi R, Devesa SS, Schairer C, Fraumeni Jr JF (2006) Rapidly increasing incidence of ocular non-hodgkin lymphoma. J Natl Cancer Inst 98: 936 - 939

Persson B, Fredrikson M (1999) Some risk factors for non-Hodgkin's lymphoma. Int J Occup Med Environ Health 12: 135-142

Ponzoni M, Ferreri AJ, Guidoboni M, Lettini AA, Cangi MG, Pasini E, Sacchi L, Pecciarini L, Grassi S, Dal CE, Stefano R, Magnino S, Dolcetti R,
Doglioni C (2008) Chlamydia infection and lymphomas: association beyond ocular adnexal lymphomas highlighted by multiple detection methods. Clin Cancer Res 14: 5794-5800

Sprague LD, Schubert E, Hotzel H, Scharf S, Sachse K (2009) The detection of Chlamydophila psittaci genotype C infection in dogs. Vet J 181: $274-279$

Svec MA, Ward MH, Dosemeci M, Checkoway H, De Roos AJ (2005) Risk of lymphatic or haematopoietic cancer mortality with occupational exposure to animals or the public. Occup Environ Med 62: $726-735$

Tarsitano E, Greco G, Decaro N, Nicassio F, Lucente MS, Buonavoglia C, Tempesta M (2010) Environmental monitoring and analysis of faecal contamination in an urban setting in the city of Bari (Apulia region, Italy): health and hygiene implications. Int J Environ Res Public Health 7: $3972-3986$

Tranah GJ, Bracci PM, Holly EA (2008) Domestic and farm-animal exposures and risk of non-Hodgkin's lymphoma in a population-based study in the San Francisco Bay Area. Cancer Epidemiol Biomarkers Prev 17: $2382-2387$ 